\title{
Cultivo do tabaco no sul do Brasil: doença da folha verde e outros agravos à saúde
}

\author{
Tobacco cultivation in the south of Brazil: \\ green tobacco sickness and other health problems
}

Deise Lisboa Riquinho ${ }^{1}$

Élida Azevedo Hennington ${ }^{2}$

${ }^{1}$ Curso de Enfermagem, Universidade Federal do Rio Grande do Sul. R. São Manoel 963/220, Rio Branco. 90620-102 Porto Alegre RS Brasil. deise. riquinho@gmail.com ${ }^{2}$ Escola Nacional de Saúde Pública, Fundação Oswaldo Cruz.

\begin{abstract}
The scope of this study was to identify the presence of health problems and their significance for tobacco harvesters, State representatives, civil society and the tobacco industry, and also understand their coping strategies. An ethnographic study with 35 semi-structured interviews answered by harvesters' families and key informants was carried out in a rural community in the state of Rio Grande do Sul. In addition to that, participant observation of the families was conducted. The harvesters and representatives of civil society acknowledge the presence of green tobacco sickness and other problems. Representatives of healthcare organizations do not identify or recognize the sickness as being a consequence of the productive activity linked to tobacco. Tobacco industry representatives acknowledge that there are health problems, but blame the harvesters. The conclusion reached is that there is a need for a closer approach, monitoring and intervention by Public Authorities in tobacco-producing rural communities, seeking to develop surveillance actions and promote occupational health.
\end{abstract}

Key words Health of the rural population, Tobacco, Public health, Qualitative research, Anthropology
Resumo O objetivo do estudo foi identificar a presença de problemas de saúde e outros agravos e seus significados para agricultores do tabaco, representantes do Estado, da sociedade civil, da indústria do tabaco e estratégias de enfrentamento. Foi desenvolvido estudo do tipo etnográfico com realização de 35 entrevistas semiestruturadas entre famílias de agricultores e informantes-chave, $e$ observação participante das famílias em localidade rural do $R S$. Os resultados evidenciaram o reconhecimento da presença da Doença da Folha Verde do Tabaco (DFVT) e outros agravos por parte dos agricultores e representantes da sociedade civil. Representantes da área da saúde não reconhecem problemas de saúde desta população como resultado da atividade produtiva vinculada ao tabaco. Os representantes da indústria admitem a existência de problemas de saúde, porém culpabilizam os agricultores. Conclui-se que é preciso maior aproximação, acompanhamento e intervenção do Poder Público em comunidades rurais que produzem tabaco, visando desenvolver ações de vigilância e promover a saúde do trabalhador.

Palavras-chave Saúde da população rural, Tabaco, Saúde pública, Pesquisa qualitativa, Antropologia 


\section{Introdução}

O Brasil é o maior exportador mundial de folha de tabaco e o Estado do RS o maior produtor brasileiro $^{1}$. O cultivo do tabaco se concentra em pequenas propriedades rurais, desenvolvido em regime de agricultura familiar ${ }^{2}$.

$\mathrm{O}$ adoecimento relacionado aos modos de produção entre trabalhadores rurais plantadores de tabaco no Brasil ainda é pouco documentado na literatura. As principais formas de adoecimento referidas em estudos internacionais e nacionais são a doença da folha verde do tabaco (DFVT), doenças respiratórias e intoxicações por agrotóxicos e decorrentes de outros agravos, como acidentes de trabalho ${ }^{3}$.

O primeiro registro conhecido sobre a DFVT foi feito na Itália por Bernardino Ramazzini, no século XVIII, e os sintomas descritos eram dores de cabeça e problemas estomacais ${ }^{4}$. Cerca de dois séculos depois a doença passou a ser largamente estudada nos EUA e, em 1970, ela foi descrita na Flórida como uma doença específica dos trabalhadores rurais do tabaco ${ }^{5}$. A DFVT decorre do estímulo ou inibição de receptores no sistema nervoso central levando a um quadro clínico de vômitos, náuseas, tonturas e cefaleia, dores abdominais, diarreia, alterações da pressão arterial e da frequência cardíaca durante ou após a exposição à Nicotiana tabacum ${ }^{6}$.

No Brasil, há três estudos epidemiológicos, dois do tipo caso controle que identificaram DFVT entre agricultores: um deles desenvolvido na cidade de Arapiraca, Alagoas, no ano de 2007, o outro em Candelária, RS, no ano de $2008^{7,8}$ e o terceiro estudo ${ }^{9}$, do tipo transversal, que desvelou a prevalência da DFVT na cidade de São Lourenço, RS, no ano de 2011. Nos primeiros dois estudos, as informações clínicas (presença de vômito, náusea, dor de cabeça e tontura) e laboratoriais (exame da saliva para medição da cotinina - metabólico da nicotina) confirmaram a ocorrência da DFVT. Houve predomínio do sexo masculino entre os acometidos e a maioria deles era proprietário das terras cultivadas. No terceiro estudo, a prevalência encontrada para a DFVT entre os homens foi de 6,6\%, e $11,9 \%$ entre as mulheres 9 . Segundo os autores, a prevalência maior entre as mulheres pode estar relacionada com diferenças biológicas, as mulheres possuem área dérmica relativamente maior em relação ao volume do seu corpo, facilitando a absorção de nicotina. Além disso, as mulheres tendem a relatar os sintomas com mais precisão do que os homens. A divisão sexual do trabalho também pode influenciar em tais resultados, por meio das diferenças na intensidade e frequência das tarefas executadas, como, por exemplo, ter mais contato com fumo seco ou colhê-lo molhado ${ }^{7,9}$.

Os problemas respiratórios são consequência do contato com a poeira da folha do tabaco e do processo de secagem, que ainda foram pouco estudados. As lesões musculoesqueléticas descritas na literatura em sua maioria decorrem de acidentes de trabalho, especialmente por quedas ${ }^{10,11}$.

O cultivo do tabaco destaca-se também pelo trabalho árduo e pela aplicação de grande volume e variedade de agrotóxicos utilizados em diferentes fases do plantio, como por exemplo, fungicidas, acaricidas, herbicidas e inseticidas, especialmente do tipo organofosforados, do semeio à colheita. $\mathrm{O}$ uso desses produtos acarreta diversos problemas para a saúde humana ${ }^{12-16}$.

Este estudo teve por objetivo identificar a presença de doenças e outros agravos e seus significados para agricultores do tabaco, representantes do Estado, representantes de organizações da sociedade civil e da indústria do tabaco em localidade rural no sul do Brasil, bem como as estratégias de enfrentamento.

\section{Percurso metodológico}

Foi desenvolvido estudo qualitativo do tipo etnográfico em uma localidade rural no interior do RS. O nome do município e da localidade de estudo será mantido em sigilo por expor práticas de trabalho por vezes em desacordo com as normas impostas pelas indústrias fumageiras que lá atuam, tais como o não uso de equipamento de proteção individual (EPI) e a presença de trabalho infantil, o que poderia gerar retaliações e prejuízos para a comunidade em questão. As indústrias também não serão identificadas.

Os sujeitos de pesquisa foram 23 famílias produtoras de fumo, todas ligadas direta ou indiretamente à indústria do tabaco. Além das famílias, foram entrevistados cinco representantes do setor saúde, quatro de organização da sociedade civil e três da indústria do tabaco (Quadro 1), totalizando 35 entrevistas.

A amostra estudada foi intencional e os entrevistados foram indicados por informanteschave da comunidade. Em relação às famílias dos agricultores, buscou-se contemplar a heterogeneidade social da comunidade pesquisada: diferentes arranjos familiares e famílias que tinham entre seus membros crianças em idade escolar. Também foram contempladas diferentes etnias e 
Quadro 1. Caracterização dos atores entrevistados: representantes do Estado, de organizações da sociedade civil e indústria.

\begin{tabular}{|c|c|c|c|}
\hline \multicolumn{4}{|c|}{ Representantes do Estado - Setor Saúde } \\
\hline Órgão & Profissão & Atividade Principal & $\begin{array}{l}\text { Idade } \\
\text { (anos) }\end{array}$ \\
\hline $\begin{array}{l}\text { Centro de Referência em Saúde do } \\
\text { Trabalhador-CEREST Regional }\end{array}$ & Enfermeira & $\begin{array}{l}\text { Presta cuidados de enfermagem no } \\
\text { Cerest há nove anos. }\end{array}$ & 36 \\
\hline $\begin{array}{l}\text { Secretaria Municipal da Saúde - } \\
\text { Vigilância em Saúde (SMS-VS) }\end{array}$ & $\begin{array}{l}\text { Economia } \\
\text { doméstica }\end{array}$ & Coordenadora da VS há nove anos. & 50 \\
\hline SMS & Médico 1 & $\begin{array}{l}\text { Trabalha há } 16 \text { anos no município } \\
\text { atendendo nas localidades rurais, } \\
\text { quinzenalmente. }\end{array}$ & 50 \\
\hline SMS & Médica 2 & $\begin{array}{l}\text { Trabalha há sete anos no pronto } \\
\text { atendimento municipal. }\end{array}$ & 46 \\
\hline Hospital Regional Filantrópico & Médico 3 & $\begin{array}{l}\text { Coordenador e plantonista do Pronto } \\
\text { Socorro do Hospital Filantrópico } \\
\text { Regional }\end{array}$ & 53 \\
\hline \multicolumn{4}{|c|}{ Representantes de Organizações da Sociedade Civil } \\
\hline $\begin{array}{l}\text { Sindicato dos Trabalhadores Rurais } \\
\text { (STR) }\end{array}$ & Agricultor & $\begin{array}{l}\text { Participa do programa do crédito } \\
\text { fundiário }\end{array}$ & 49 \\
\hline STR & Agricultor & $\begin{array}{l}\text { Participa do programa do crédito } \\
\text { fundiário }\end{array}$ & 59 \\
\hline $\begin{array}{l}\text { Centro de Apoio ao Pequeno } \\
\text { Agricultor (CAPA) }\end{array}$ & $\begin{array}{l}\text { Técnico em } \\
\text { enfermagem }\end{array}$ & $\begin{array}{l}\text { Desenvolve ações de educação e saúde } \\
\text { junto aos agricultores }\end{array}$ & 46 \\
\hline $\begin{array}{l}\text { União das Associações } \\
\text { Comunitárias (UAC) }\end{array}$ & Técnico agrícola & $\begin{array}{l}\text { Estimula a produção agroecológica e o } \\
\text { cooperativismo }\end{array}$ & 31 \\
\hline Líder Comunitário (LC) & $\begin{array}{l}\text { Professor } \\
\text { aposentado }\end{array}$ & $\begin{array}{l}\text { Líder religioso e membro da associação } \\
\text { local }\end{array}$ & 54 \\
\hline \multicolumn{4}{|c|}{ Representantes da indústria } \\
\hline Indústria 1 & $\begin{array}{l}\text { Técnico em } \\
\text { contabilidade }\end{array}$ & $\begin{array}{l}\text { Instrutor da indústria } 1 \text {. Responsável } \\
\text { pela captação dos agricultores no início } \\
\text { do plantio e acompanhamento da } \\
\text { atividade, como pedidos de insumos e a } \\
\text { comercialização. }\end{array}$ & 31 \\
\hline Indústria 2 & Técnico agrícola & $\begin{array}{l}\text { Instrutor da indústria } 2 \text {. Idem ao } \\
\text { primeiro. }\end{array}$ & \\
\hline Indústria 3 & Técnico agrícola & $\begin{array}{l}\text { Instrutor da indústria 3. Idem ao } \\
\text { primeiro. }\end{array}$ & 50 \\
\hline
\end{tabular}

Fonte: Riquinho e Hennington ${ }^{3}$. 
distintos credos, famílias com presença de filhos menores de 18 anos. Havia famílias vinculadas à indústria pelo sistema integrado, famílias que compravam todos os insumos em lojas agropecuárias e comercializavam para diferentes indústrias e atravessadores e ainda famílias com e sem dívida acumulada com a indústria.

Entre as famílias entrevistadas, o principal arranjo foi nuclear, formado pelo casal e filhos, seguido por apenas a presença do casal. A maioria se identificava como "brasileiro" e a seguir como "alemão" ou "pomerano". A religião mais referida foi católica ou luterana. A idade dos agricultores entrevistados variou entre 28 a 70 anos com maior concentração etária dos 30 aos 50 anos. A média de integrantes das famílias foi de 3,4 pessoas. A maioria dos pais possuía o ensino fundamental incompleto e os filhos em idade escolar frequentavam a escola, exigência da indústria. O tempo de trabalho no cultivo do fumo variou entre 2 a 17 anos, com uma média de 7,7 anos, havendo dois casos de mais de 30 anos de cultivo.

Durante as entrevistas com os agricultores, as famílias estavam reunidas, sendo possível o diálogo com todos os integrantes, mesmo os filhos menores de 18 anos. Com os representantes do Estado, de organizações da sociedade civil e indústria, as entrevistas foram agendadas e realizadas individualmente em seus locais de trabalho.

Realizou-se observação participante com cinco das 23 famílias entrevistadas, visando acompanhar o cotidiano de trabalho, suas rotinas e práticas no cultivo do tabaco. O trabalho de campo ocorreu durante 90 dias, de dezembro a agosto de 2011. A escolha deste período se justifica por oportunizar o acompanhamento de um ciclo completo de trabalho no cultivo do tabaco, do semeio à classificação do fumo.

O estar "com" os participantes da pesquisa, observar seus modos de vida, bem como a relação com eles estabelecida repercutiram no material analisado. Esta interação pesquisador e pesquisado, o encontro do conhecimento científico e senso comum é entendido por Geertz ${ }^{17}$ como a "ciência da interação" e, portanto, interpretativa. O tratamento do material produzido a partir das entrevistas e da observação ocorreu por meio de categorização temática ${ }^{18}$.

O projeto de pesquisa foi submetido e aprovado pelo Comitê de Ética em Pesquisa da Escola Nacional de Saúde Pública Sergio Arouca.

\section{Resultados e Discussão}

Os significados atribuídos pelos sujeitos ao adoecimento como consequência do cultivo do fumo foram organizados em três categorias: "a doença da folha verde do tabaco", "outras doenças e agravos" e "o enfrentamento dos problemas de saúde". Os significados dos fenômenos vividos no cotidiano são explicados a partir da visão de mundo das famílias. Nesta perspectiva, as pessoas elaboram os fatos, seu conceito da natureza, de si mesmo e da sociedade a partir da realidade que vivem $^{19}$. Antes de passarmos às categorias analíticas, apresentaremos um breve histórico do lócus da pesquisa.

\section{Histórico e características locais}

O município pesquisado apresenta $63 \%$ da população vivendo no meio rural $^{20}$. As características fundiárias da localidade pesquisada são de pequenas propriedades ( 0,5 a 20 hectares).

Em relação ao histórico da produção rural, as famílias praticavam o extrativismo de madeira nativa para lenha, trocando nos armazéns das proximidades por alimentos, como sal e café. Havia também a venda de excedentes da produção de frutas e outros cultivos. No final da década de 1970 dá-se início à relação dos agricultores com a indústria.

Este período, segundo os entrevistados, é marcado pelo calote da indústria, atraso e parcelamento da dívida com os agricultores. Este cenário desfavorável na comercialização, em especial do pêssego, levou-os a um novo ciclo, o cultivo do tabaco:

Tinha que fazer tudo por conta própria na plantação de pêssego. E da firma de fumo vêm os defensivos, vem a semente, vem o que precisa para trabalhar, apenas a pessoa vai entrar para trabalhar, com o trabalho dele e depois pagar a produção (Família 1).

O cultivo do fumo é mantido por um sistema denominado integrado: a indústria oferece as condições para o trabalho, financia a estrutura dos galpões e estufas para armazenamento e cura do tabaco, fornece sementes e agrotóxicos para cada etapa do processo do cultivo, viabiliza a visita periódica de um instrutor e a compra do produto final. Apesar dos prováveis ganhos financeiros na troca do cultivo do pêssego pelo fumo, esta população passou a enfrentar novas doenças e agravos decorrentes da mudança de cultivo. 
pesavam mal [as filhas]. Mas, se elas iam com o sereno da manhã, elas iam a apanhar, começava aquela nicotina a vim vindo, quando chegava ali pelas 9, 10 horas elas já arriavam, elas não podiam mais, vômito e ai aquele suador, aquela coisa, aquela tontura, elas tinham que parar, então ai a gente foi observando que era do fumo molhado (Família 2).

A planta do tabaco pronto para a colheita atinge pelo menos a altura de 1 metro e 20 centímetros cercando o corpo do trabalhador. Os agricultores colhem o tabaco, quebrando as folhas do caule e armazenando-as sob o braço. O significado atribuído ao fumo molhado em contato com o corpo por dois dos agricultores está associado à nicotina atingindo o fígado. Tal elaboração parece vinculada à localização deste órgão e as suas funções auxiliares do processo digestivo.

Aqui não, eu aqui não, mas quase todos existe essa parte, não é só numa família, quase todos se queixam, ou não podem apanhar fumo molhado, porque o fumo molhado quando atinge, ele tem nicotina, ele atinge o figado, esse lado sempre [lado direito] (Família 21).

Segundo o líder comunitário, após colheita de fumo cedo da manhã, quando as folhas estão molhadas pelo sereno ou após chuva, os agricultores costumam relatar que sentem tontura, náuseas, vômito e desmaios. Ele afirma ainda que as crianças também ficam doentes: "foi os quatro da casa, eles os dois e as duas crianças foram pro hospital, choveu e foram apanhar o fumo, quando foi de tardezinha foram pro hospital".

Uma forma de adoecimento pouco referida na literatura, mas relatada em entrevista é a alteração visual provocada pela intoxicação aguda da nicotina, a qual foi descrita na Polônia associada aos demais sintomas de DFVT ${ }^{21}$ :

A [nome da filha], passou tão mal que vó te dizê, ela tava perdendo até a visão, num dia dela apanhar o fumo molhado, tava perdendo a visão. Ela dizia: mãe acho que vou perder minha visão de tudo, não enxergo quase mais nada. Ai me apavorei, meu Deus do céu (Família 2).

De acordo com os entrevistados, o adoecimento associado à nicotina atinge indistintamente mulheres, homens e crianças. Há relatos de adoecimento entre crianças de 10 anos, jovens de 16 e 18 anos e ainda adultos de 40 a 50 anos. Há relatos sobre crianças de 10 anos, jovens de 16 e 18 anos e ainda adultos de 40 a 50 anos. De acordo com a literatura, as consequências desta exposição a médio-longo prazos não são claramente definidas. Estudo na Îndia identificou maior prevalência de hipertensão e de partos prematuros em agricultoras do tabaco em relação ao grupo controle $^{22}$. No entanto, segundo os próprios autores, essas diferenças não foram estatisticamente significativas nem são resultados definitivos, devido ao tamanho da amostra, ausência de estudos comparativos e diferentes quantidades de nicotina absorvida durante as várias etapas do processo de cultivo de tabaco ${ }^{22}$.

$\mathrm{Na}$ agricultura, $70 \%$ da força de trabalho é infantil e a monocultura destaca-se no emprego deste contingente de trabalhadores ${ }^{23}$. As crianças estão expostas a agrotóxicos, ao risco de doenças e acidentes pelo uso de máquinas agrícolas e, no caso do tabaco, à DFVT. Devido à imaturidade fisiológica, biológica e psicológica inerentes ao processo de crescimento, as crianças são mais vulneráveis que os adultos aos riscos ocupacionais ${ }^{24,25}$. No entanto, as consequências da exposição aos agentes de doenças e acidentes de trabalho em alguns casos ficarão evidentes somente na vida adulta com o surgimento de cânceres, infertilidade e doenças osteomusculares, dentre outros problemas ${ }^{23,26}$. Não foram encontrados estudos que indiquem os efeitos da DFVT na saúde das crianças.

Em relação ao uso de equipamento de proteção individual, as roupas impermeáveis fornecidas pela indústria fumageira por hectare plantado e depois cobradas na compra do fumo, dificilmente são usadas devido ao calor do sol. Constatou-se que depois de lavadas elas perdem a ação impermeável, devendo ser descartadas após o uso. Entretanto, os agricultores costumam reutilizá-las, provavelmente devido ao preço de cada vestimenta, em torno de trinta reais. Estudo de Arcuryet al..$^{27}$ demonstrou que luvas e roupas de proteção contra a chuva diminuem a absorção da nicotina e a presença de lesões preexistentes nas mãos e axilas, porém, na maioria das vezes, EPI não são utilizados por dificultarem o processo de colheita.

\section{Outras doenças e agravos}

Foram observados e referidos durante o trabalho de campo mais três tipos de problemas de saúde entre os agricultores, como consequência 
ou agravados pelo trabalho com o fumo: doenças respiratórias, acidentes e intoxicações por agrotóxicos.

\section{Doenças respiratórias}

A exposição dos trabalhadores à poeira das folhas secas do tabaco, resultantes do processo de cura, concentra nicotina e outras substâncias químicas, resultando em possíveis danos ao sistema respiratório, especialmente pela não utilização de proteção respiratória durante essas etapas do cultivo $^{13}$. Dentre os agricultores foi relatada doença respiratória como conseqüência do contato com a poeira das folhas e o adoecimento de crianças por bronquite, a qual se agrava pelo contato com as folhas do fumo seco.

Nós somos sadios, só tenho os guris que são assim doentinhos. Eu tenho esse, o [nome do filho], ele é doente de bronquite, desde que nasceu, é alérgico também, não pode ter contato muito com fumo, não pode ir no paiol (Família 7).

O processo do cultivo do tabaco comumente envolve as crianças da família, mesmo que oficialmente a indústria proíba o trabalho de menores de 18 anos. Por se tratar de uma atividade familiar, as crianças dela participam efetivamente trabalhando a partir dos 10 anos e os menores repetem as tarefas dos pais como a classificação das folhas e dividem o mesmo ambiente em que fica armazenado o fumo primeiramente verde e depois seco. Neste segundo momento (fumo seco), seu cheiro é marcante com notas adocicadas que impregnam o ar, causando desconforto ao sistema respiratório superior nos menos habituados, surgindo prurido e ardência na boca e nariz.

\section{Acidentes}

Os acidentes relatados se referem a quedas da carroça no transporte do fumo da lavoura para a estufa e na própria estufa. Depois das folhas do fumo colhidas, elas são envolvidas por um pedaço de pano/lona, formando feixes de folhas que são depositados em uma carroça. Para o aproveitamento do transporte, as carretas ficam por vezes sobrecarregadas. Então, alguém acompanha o trajeto para evitar perder fumo pelo caminho, sentado em cima dos feixes ou de pé na carroça, atividade que pode ser feita por criança ou adulto. Segundo relatos, houve caso de fratura no antebraço de uma criança e de costelas em um adulto. Os agricultores familiares estão inseridos em um grupo especial para a Previdência Social, quando efetuados pedidos de aposentadorias, pensões ou afastamento por doença/acidentes, sendo necessária a mediação de uma associação, como a do sindicato dos trabalhadores rurais, visto que não contribuem diretamente como os trabalhadores de áreas urbanas. Nesse último caso ocorreu perda de dias de trabalho e afastamento pelo INSS.

Observou-se que as estufas são galpões de uns seis metros de altura, organizados internamente com varas de eucaliptos penduradas na horizontal para a secagem das folhas. Um agricultor sobe e outros alcançam as folhas costuradas em bambu para serem dispostas nas varas de eucaliptos.

Eu só o que eu me lembro, que tive um problema numa virilha, deu distensão, uma vez que eu caí de cima do estaleiro da estufa. Resbalei, os pés suados, eu resbalei e fiquei preso por uma perna, dói até hoje, às vezes tem dia mesmo que eu tenho que trabalhar com uma liga (Família 18).

Ao pesquisar os atendimentos de emergência em serviços de três regiões de Kentucky, EUA ${ }^{11}$, foi constatado que $23 \%$ das lesões e traumatismos estavam relacionados à produção do tabaco, a maioria por quedas, seguidos de cortes ou perfurações e por esforço físico excessivo. Mais de 90\% dos pacientes feridos precisaram de acompanhamento em ambulatório.

\section{Intoxicações por agrotóxicos}

No cultivo do tabaco os agrotóxicos são aplicados manualmente ou usando pulverizadores back-pack, um tipo de bolsa de acrílico carregada nas $\operatorname{costas}^{14}$. Essa aplicação quando combinada com a falta de equipamentos de proteção, tais como vestimentas impermeáveis, máscaras, luvas, e botas, leva à exposição de doses concentradas que podem ser absorvidas por via oral, dérmica e inalação. Outras formas de contaminação foram observadas por meio da lavagem das vestimentas e nas diluições dos agrotóxicos. Tais atividades tornam os agricultores vulneráveis às intoxicações agudas e crônicas causadas pelos produtos manipulados nas diferentes fases do plantio ${ }^{13}$.

Uma das formas de contato dos agricultores com os agrotóxicos é quando os produtos são aplicados nas mudas antes destas serem transplantadas para a terra, quando estão em piscinas (sistema float). Em alguns casos ocorre "rejeição": as mudas não desenvolvem e então os agricultores retiram-nas individualmente e lavam em água corrente para retirar o excesso de veneno. Tal qual apontado por Peres et al. ${ }^{28} \mathrm{em}$ seu estudo, também nesta pesquisa observou-se que as mulheres estão igualmente expostas à contaminação 
por agrotóxico. Na produção do fumo, elas participam e desenvolvem a aplicação de agrotóxicos em diferentes etapas do processo do cultivo.

Outra forma de contaminação ocorre ao carregarem a back-pack com 25 litros de veneno para pulverizarem a plantação sem nenhuma proteção, a não ser um boné para atenuar os efeitos do sol. Alguns vestem camisas de manga comprida para tentar proteger-se um pouco mais. As aplicações são feitas tanto ao sol como em dias chuvosos. Em uma das fases do processo de trabalho, na floração do pé de fumo, uma haste com flores no ápice da planta é quebrada manualmente. Enquanto uns fazem este trabalho, outros os seguem aplicando o agrotóxico em cada planta.

Alguns depoimentos sobre adoecimento referem-se a casos de depressão com acompanhamento de saúde e também tratamento medicamentoso a reações cutâneas.

Foi em agosto que eu me estraguei. Um sábado eu apliquei Talstar e o Mozo. E aí, no início da semana, apliquei outro, o Boral. Queimou toda perna, até onde vai o plástico, uma parte da roupa. Agora já tá sarado, mas até aqui em cima era só uma ferida, chegava a correr sangue. Não sei qual é eles que faz mal, eu não sei, mas eles tinham que fazer análise, eles não... até agora não apareceram [represente da fumageira] (Família 19).

O Talstar é um inseticida do grupo piretroide. $\mathrm{Na}$ descrição dos sinais e sintomas resultantes das intoxicações agudas podem ocorrer dentre outras, reações dérmicas, pruridos e sensação de ardor na pele ${ }^{29}$. Sobre o produto referido como Boral, este é um herbicida pré-emergente que deve ser colocado na terra antes do início do plantio; as informações de tal produto não o associam a alterações dérmicas. Apesar de serem considerados de pouca toxicidade à saúde humana, estes agrotóxicos são considerados altamente tóxicos ao ambiente ${ }^{29}$. Em relação ao veneno denominado Mozo, não foram encontradas informações na literatura, e nem por meio do contato com engenheiros agrônomos foi possível obter qualquer informação sobre este produto.

Como recorda o entrevistado, mesmo fazendo uso do EPI fornecido pela indústria, houve o contato com o produto e consequente lesão cutânea. Após o ocorrido o agricultor comunicou o instrutor da indústria fumageira, porém não houve análise ou identificação do produto que o atingiu. Com o tratamento a base de corticoide em consultório particular, houve uma aparente melhora.

Eu melhorei, trabalhei de novo no fumo e foi tudo de novo, antes do meio-dia eu apanhei, não senti nada. Aí, depois do meio-dia, fomos pra la- voura de novo e não consegui, tirei, não cheguei a tirar duas braçadas, ai tive que voltar pro médico de novo. Só precisa ir à lavoura onde foi usado o veneno, atravessar e deu, já começa de novo, já volta de novo (Família 19).

Os agricultores acometidos por doenças e agravos causados pelo cultivo do tabaco, ainda que sem muitas informações técnicas ou científicas sobre seu processo de trabalho e as consequências para a saúde, estabelecem relação clara entre esta atividade e o adoecimento. No entanto, não foi relatado pela maioria das famílias preocupação em relação a piora do estado de saúde a longo prazo ou perspectivas de manterem as condições para o trabalho futuramente.

Para os representantes de organizações da sociedade, devido a sua origem ou proximidade com a agricultura, já presenciaram ou ouviram relatos de intoxicações acidentais ao uso de agrotóxico. Essas são recorrentes do não uso ou do uso inadequado dos EPI, por várias alegações, como, "não gostar de usar" ou "por atrapalhar o trabalho". Como consequência da exposição aos agrotóxicos, os entrevistados acreditam, pelas suas observações e vivências, que o município apresenta muitos casos de depressão: "as casas de saúde mental estão lotadas de gente por causa de depressão” (CAPA). E também casos de câncer, "eu tive uma experiência muito triste: um amigo, nos criamos juntos e ele ficou lá plantando fumo, faleceu aos 32 anos. O médico disse: não posso dizer para vocês que o câncer foi devido ao uso de agrotóxico" (UAC).

A relação entre exposição a agrotóxicos e diversos tipos de câncer, vêm sendo estudada em todo o mundo, com evidências desta associação especialmente em relação aos compostos organoclorados e alguns herbicidas, embora no plantio do fumo destacam-se os organofosforados ${ }^{30}$. Estudos $^{31,32}$ encontaram variação genética pelo uso de agrotóxicos associada ao risco de câncer de próstata em exposições ao brometo de metila e aos organoclorados. Em um estado brasileiro, o aumento na utilização de agrotóxicos coincidiu com o aumento da mortalidade por neoplasia ${ }^{33}$. No entanto, apesar de algumas pesquisas indicarem associação entre câncer e uso de agrotóxicos, como de próstata, retal e de pulmão, suas estimativas por vezes são imprecisas devido a erros de classificação e de exposição ${ }^{34}$.

Outro potencial problema para a saúde decorrente da utilização de agrotóxicos é o reaproveitamento do solo utilizado para plantação de fumo e de diversos cultivos no mesmo terreno. Segundo representante do CAPA, os agricultores 
semeiam hortaliças e frutas tanto nas bandejas das mudas de tabaco quanto nas lavouras junto às plantações.

\section{Enfrentamento dos problemas de saúde}

Nos casos de DFVT, decorrente da colheita do fumo molhado, alguns agricultores procuram os serviços de saúde para a recuperação:

$O$ [nome do filho], é só trabalhar no fumo molhado. Treme, chega de noite, vômito, tontura, escurece as vista da gente, que coisa, é horrivel. Há poucos dias foi pro pronto-socorro, eles colocam soro na gente, na veia (Família 16).

Os agricultores queixam-se de dificuldade de acesso ao atendimento no serviço de saúde municipal, especialmente em decorrência da forma de organização da demanda. Como são distribuídas fichas no Pronto Atendimento, quem vem da zona rural espera pelo atendimento; mesmo saindo cedo de casa pela manhã, são atendidos no turno da tarde. Outro local procurado para atendimento é o Pronto Socorro, vinculado ao hospital filantrópico do município. Neste, mesmo que haja atraso no atendimento devido às trocas de plantão, as pessoas dizem que o atendimento é mais ágil.

Foi mencionado pelos agricultores que procuram atendimento no Pronto Socorro que alguns médicos reconhecem os sintomas apresentados por eles como consequência do trabalho e orientam evitar o contato com folhas molhadas ou até mesmo o cultivo do fumo. No entanto, os agricultores dizem desconhecer ações de vigilância em saúde do trabalhador; os atendimentos não geram nenhuma notificação ou acompanhamento pelos profissionais de saúde. O tratamento da DFVT é baseado na administração de agentes com atividade anticolinérgica como antieméticos, anti-histamínico e medidas de suporte como hidratação e repouso ${ }^{35}$.

Foi observada em relação às falas dos entrevistados do setor saúde certa ambiguidade em relação ao diagnóstico da DFVT; por vezes negam sua ocorrência e, em outras, a denunciam. A responsável pela vigilância em saúde do município recorda que ouviu falar deste agravo em um treinamento do Ministério da Saúde em 2008.

O diretor do hospital e plantonista do pronto socorro diz que alguns agricultores chegam ao serviço de saúde com queixa típicas da DFVT e reitera que não são muitas pessoas, mas sempre que as atende, preocupa-se com o uso de EPI:

Sempre que eles vêm a gente pergunta assim: "vem cá, tu tá usando máscara, tu tá usando luva, tu tá usando isso, tá usando aquilo?" - "Não, não, não uso." - "Tá, mas porque que tu não usa, se o teu instrutor tá dizendo que tu tem que usar?" "Ah! porque é muito calor, é muito abafado, é muito isso, muito aquilo" (Médico 3).

Os representantes da indústria, ao falarem sobre problemas de saúde relacionados ao cultivo, referem-se ao não uso de EPI por parte dos trabalhadores. O instrutor 1 destaca a resistência ao uso do equipamento de proteção devido ao calor: "é complicado, mas é uma maneira de se proteger, então a gente tem que conscientizar eles e eles têm que ter consciência disso também". $\mathrm{O}$ instrutor 2 relata que a vestimenta vem juntamente com o pedido de compra a cada safra: por hectare de fumo registrado, o agricultor recebe calça e túnica de um tecido sintético e um par de luvas emborrachadas. Ele ainda alerta que este $k i t$ é apenas para a colheita do fumo úmido, devendo ser trocada quando o sol está forte.

No pronto atendimento municipal, a médica diz que é raro atender casos característicos de DFVT, mas, a seguir, descreve o atendimento de um jovem de 14 anos na semana anterior. Conta que, normalmente, este problema afeta jovens que começam a trabalhar no fumo devido à inexperiência ou falta de contato prévio com a nicotina; dificilmente pessoas mais velhas têm estas queixas. Como os sintomas são inespecíficos, ela os trata conforme orientação do Centro de Informações Toxicológicas. Conclui que, para afirmar que os casos atendidos são consequência do fumo, precisaria de exames que não dispõe para comprovar tal evidência. Afirma que fazer esta afirmação, sem o respaldo laboratorial, seria leviano e tal atitude tem acarretado processos judiciais contra médicos.

Há casos em que os agricultores referem que, para remediar os sintomas da DFVT, preferem fazer repouso, hidratação com ingestão de chás, refrigerantes e leite a procurar o serviço de saúde:

Sinceramente, eu não levei [ao hospital] porque fiquei com medo, porque é proibido, sabe(?) menor trabaiá no fumo. Eu dava leite pra elas (Família 2).

Os agricultores acreditam que o leite tem propriedades para "cortar" os efeitos do agrotóxico, expurgando do corpo as substâncias tóxi$\operatorname{cas}^{36}$. Há ainda a estratégia utilizada pelos trabalhadores de fumar durante a colheita do tabaco, a qual foi mencionada como uma forma de tolerar os sintomas da DFVT. Diversos estudos demonstram que fumar cigarro é uma estratégia usada pelos agricultores para maior tolerância à manifestação de sinais e sintomas relacionados com o cultivo do tabaco ${ }^{8,37}$. 
Da mesma forma que os agricultores identificam que os sinais e sintomas da DFVT advêm da folha do tabaco molhada, eles também mencionam que deveriam evitar ir cedo da manhã à lavoura ou não continuar o trabalho enquanto chove. Como a colheita ocorre no verão, se não forem cedo da manhã, o sol mais forte murchará as folhas do fumo, acarretando perda de qualidade, sem falar no desconforto de trabalhar ao sol do verão. No caso da colheita sob chuva, as folhas do fumo que estão prontas precisam ser processadas num breve espaço de tempo. Além disso, é necessário colher a quantidade suficiente para encher a estufa que levará sete dias para completar o processo de cura. Então, mesmo sob chuva, por vezes é necessário continuar a colheita.

Outro aspecto observado é que os resíduos da colheita das folhas do tabaco têm um aspecto de "goma" que impregnam as mãos ou luvas e também a roupa de trabalho, dando um aspecto de sujidade. E os agricultores têm noção sobre a necessidade de se lavar para evitar o adoecimento.

Em relação às doenças respiratórias, poucas são as estratégias de proteção ou recuperação da saúde. Um agricultor relatou o uso de máscara ao manusear o fumo seco e no caso citado da bronquite infantil. Há acompanhamento de saúde em um hospital de referência na capital do Estado e uso regular de medicação. Para as quedas, não foram mencionadas estratégias de prevenção e as pessoas não falam muito de sua ocorrência, como se houvesse naturalização dos episódios e, por isto, fossem considerados eventos esperados ou inevitáveis.

Quanto às intoxicações por agrotóxicos, os agricultores acreditam que observar a posição do vento e trabalhar nesta direção diminui a impregnação pelo odor do agrotóxico e, como consequência, sua absorção. Pesquisa junto a agricultores de flores ornamentais em Minas Gerais ${ }^{38}$ evidenciou nos relatos a crença de que a maneira de posicionar o corpo com relação ao vento na pulverização, minimiza os riscos de intoxicação, da mesma maneira que "evita puxar o cheiro".

$\mathrm{O}$ agricultor que teve lesões de pele após aplicação de agrotóxicos na plantação de fumo entrou com dois processos num escritório de advocacia: um contra a indústria fumageira, pela negligência na assistência à sua saúde, por não terem tomado nenhuma medida na identificação do produto que lhe causou mal, e o outro processo solicitando a aposentadoria rural.

Em relação às ações em saúde, mais especificamente as notificações da DFVT ou outras doenças e acidentes, os entrevistados dos dois ser- viços (pronto atendimento municipal e pronto socorro) revelam que atestam para afastamento, mas não como acidente de trabalho: "trabalhador de uma firma, cortou o pé, aí se preenche; ao contrário, não" (Médica 2).

Eles não têm porque são autônomos [agricultores], então não se faz. O que a gente faz é dar, no caso, eu que trabalho aqui no plantão. E eles pedem é um atestado para entrar no INSS, aí a gente dá um atestado para eles procurarem o INSS, para se encostar. Mas tinha um outro formulário antigamente, mas não, há muito tempo que não tem, desapareceu (Médica 2).

A representante do Centro de Referência em Saúde do Trabalhador pondera que o ideal seria que todos os profissionais de saúde, que atendem agravos ou acidentes de trabalho, notificassem e encaminhassem tal ocorrência, mas reconhece que isto não acontece. Muitos profissionais da rede desconhecem o papel do Cerest, sua finalidade e que estão integrados ao SUS. Uma das dificuldades apontadas é a extensão de cobertura do Cerest que tem atuação regional: são $28 \mathrm{mu}$ nicípios com uma grande diversidade produtiva, plantio de arroz, tabaco, pesca, extração e beneficiamento de madeira. Além disso, a frequente troca de gestores também se configura como fato que causa dificuldades de atuação.

Observou-se que os trabalhadores rurais do município pesquisado são desassistidos nas questões referentes à sua saúde. Não foram conhecidas ou referidas ações de vigilância em saúde no contexto produtivo do tabaco, uma das principais atividades geradoras de renda no município. Há um vazio nas ações de promoção, vigilância e assistência à saúde do trabalhador rural. A atenção primária nas localidades rurais centra seus atendimentos ocasionais à consulta médica individual, de acordo com a demanda espontânea. A Estratégia da Saúde da Família é presente na periferia urbana do município, com três unidades atendendo cerca de quatro mil pessoas. Tal estratégia ainda não atende a população rural.

É um desafio fazer cumprir a lei criada pela Portaria GM/MS n. 1.679, de 2002, que instituiu a Rede Nacional de Atenção Integral à Saúde do Trabalhador (Renast), e implementar ações de saúde do trabalhador no SUS ${ }^{38}$. Dentre as principais dificuldades identificadas pelos autores está o despreparo dos profissionais para cuidar da saúde, considerando a inserção dos trabalhadores nos processos produtivos, devido à ausência da temática na graduação e, posteriormente, nos processos de educação permanente em saúde. Além disso, as ações intersetoriais quanto à 
fiscalização dos ambientes e das condições de trabalho e a promoção de novas alternativas ao rompimento com atividades desencadeadoras de adoecimento ainda são entraves para uma atenção integral ao trabalhador ${ }^{38}$.

\section{Considerações finais}

Histórias de vida e trabalho de agricultores do tabaco de comunidade rural no sul do Brasil evidenciaram a presença de sinais e sintomas associados à DFVT e também outros agravos como doenças respiratórias, acidentes e intoxicações por agrotóxicos, corroborando a literatura acerca dos problemas de saúde relacionados a este cultivo.

Outro problema identificado é o trabalho infantil. A predominância de famílias nucleares favorece este trabalho já característico em pequenas propriedades rurais, para manter o nível de produção exigido, apesar da proibição por parte da indústria fumageira. Observou-se também a baixa escolaridade dos pais, o que certamente compromete o entendimento dos contratos firmados com a indústria fumageira e mesmo a leitura e compreensão da rotulagem e advertências ao uso de agrotóxicos.

Há o reconhecimento por parte das famílias do adoecimento como consequência, especialmente, da colheita do fumo molhado; das doenças respiratórias agravadas pela poeira das folhas secas; de acidentes por queda da estufa ou da carreta com carga de fumo e de lesões dermatológicas causadas por contato com agrotóxicos e da intoxicação associada a quadros depressivos.

No caso do setor saúde, não foi identificado nenhum registro da suspeita ou ocorrência da DFVT ou de qualquer outro acidente de trabalho envolvendo os agricultores da região. Conforme observado, o Cerest não desempenha suas funções de capacitação dos profissionais de saúde para reconhecer e notificar tal doença ou outros acidentes de trabalho e nem realiza ações de vigilância em saúde do trabalhador. Assim, não foram identificadas quaisquer ações recomendadas pela Convenção-Quadro para o Controle do Tabaco, especialmente no que refere o artigo 18 a respeito da proteção e orientação a saúde das pessoas envolvidas com o cultivo ${ }^{39}$.

É preciso uma aproximação do Estado, através de agentes da agricultura e da saúde e de outros setores do Poder Público, dos agricultores e de organizações da sociedade civil para discutir, apontar e desenvolver ações intersetoriais e incentivar alternativas ao cultivo do tabaco. Por se tratar de um grupo vulnerável, negligenciado historicamente pelas políticas públicas do trabalho, agricultura e da saúde, ou quando desenvolvidas, com forte inclinação assistencialista, há que se pensar em estratégias coletivas de intervenção que incluam os trabalhadores rurais e suas famílias em ações e práticas de proteção e promoção da saúde e no planejamento e implementação de formas viáveis de reprodução física e social.

Por fim, a partir dos relatos e observações da exposição a fatores de risco e do adoecimento de agricultores do tabaco, e da constatação da falta de ações na área da saúde do trabalhador, esperase ter contribuído para (re) afirmar a vulnerabilidade destes trabalhadores, reforçando a necessidade de uma atuação intersetorial e o importante papel da saúde do trabalhador na vigilância, prevenção e tratamento de agravos e doenças ocupacionais dos trabalhadores rurais do tabaco $\mathrm{e}$ da decisiva participação do controle social para a transformação dessa realidade.

\section{Colaboradores}

DL Riquinho trabalhou na concepção do artigo, metodologia, pesquisa e escrita final e EA Hennington participou de todas as etapas do trabalho orientando e revisando o periódico. 


\section{Referências}

1. Deser 2005. A cadeia produtiva do fumo. [acessado 2009 out 17]. Disponível em: http://www.deser.org.br

2. Associação dos Fumicultores do Brasil (AFUBRA). Fumicultura no Brasil 2009. [acessado 2009 out 17]. Disponível em: http://www.afubra.com.br

3. Riquinho DL, Hennington EA. Health, environment and working conditions in tobacco cultivation: a review of the literature. Cien Saude Colet 2012; 17(6): 1587-1600.

4. Eckholm E. Cutting tobacco's toll. British-American Tobacco Company 20; 1978.

5. Weizenecker R, Deal WB. Tobacco cropper's sickness. J Fla Med Assoc 1970; (57):13-14

6. Arcury TA, Quandt SA, Garcia DI, Preisser Junior JS, Norton D, Rao P. Clinic-based, case-control comparison of green tobacco sickness among minority farmworkers: clues for prevention. South Med 2002; 95(95):1008-1011.

7. Bartholomay P, Iser B, Oliveira P, Santos T, Feistler A, Malta D, Sobel J, De Moura L. Epidemiologic investigation of an occupational illness of tobacco harvesters in southern Brazil, a worldwide leader in tobacco production. Occup Environ Med 2012; 69(7):514-518.

8. Oliveira PPV, Sihler CB, Moura L, Malta DC, Torres MCA, Lima SMCP, De Lima ALA, Leite CE, Da Costa-e-Silva VL, Sobel J, Lanzieri TM. First reported outbreak of Green tobacco sickness in Brazil. Cad Saude Publica 2010; 26(12):2263-2269.

9. Fassa AG, Faria NMX, Meucci RD, Fiori NS, Miranda VI, Facchini LA. Green Tobacco Sickness Among Tobacco Farmers in Southern Brazil. Am J Ind Med 2014; 57(6):223-300.

10. Pugh KJ, Pienkowski D, Gorczyca JT. Musculoskeletal trauma in tobacco farming. Orthopedics 2000; (23):141-143

11. Struttmann TW, Reed DK. Injuries to tobacco farmers in Kentucky. South Med J 2002; 95(8):850-856.

12. Instituto Nacional de Câncer (Inca). Tabaco e pobreza: um círculo vicioso. Rio de Janeiro: Inca; 2004.

13. Arcury TA, Quandt SA. Health and social impacts of tobacco production. J Agromedicine 2006; 11(3-4):7181.

14. Loker WM. The rise and fall of flue-cured tobacco in the Copán Valley and its environmental and social consequences. Human Ecology 2005; 33(3):299-327.

15. Lima RG. Desenvolvimento técnico-produtivo da lavoura de tabaco na bacia hidrográfica do Rio Pardinho, RS. In: Etges VE, Ferreira MAF, organizadores. A produção do tabaco: impacto no ecossistema e na saúde humana na região de Santa Cruz do Sul, RS. Santa Cruz do Sul: EDUNISC; 2006. p. 198-224.

16. Yokoyama K. Our recent experiences with sarin poisoning cases in Japan and pesticide users with references to some selected chemicals. Neuro Toxicology 2007; (28):364-373

17. Geertz C. Nova luz sobre a antropologia. Rio de Janeiro: Jorge Zahar Editor; 2001.

18. Minayo MCS. O desafio do conhecimento. 10a Ed. São Paulo: Hucitec; 2007.

19. Geertz C. A Interpretação das culturas. Rio de Janeiro: LTC; 2008.
20. Instituto Brasileiro de Geografia e Estatística (IBGE) 2010. Cidades. [acessado 2012 mar 15]. Disponível em: http://www.ibge.gov.br/cidadesat/topwindow.htm?1

21. Satora L, Oszcz H, Gomólka E, Biedron W. Diplopia in Green Tobacco Sickness. J Agromedicine 2009; 14(1):66-69.

22. Parikh JR, Gokani VN, Doctor PB, Kulkarni PK, Shah AR, Saiyed HN. Acute and chronic health effects due to green tobacco exposure. Am J Ind Med 2005; 47 (6):494499.

23. Word Health Organization (WHO). 2014. Hazardous child labour. [acessado 2014 mar 5]. Disponível em: http://www.who.int/occupational_health/topics/child labour/en/

24. Fassa AG, Facchini LA, Dall'Agnol MM, Christiani DC. Child labor and health: problems and perspectives. Int J Occup Environ Health 2000; 6(1):55-62.

25. O'Donnell O, Doorslaer EV, Rosati FC. Child labour and health: evidence and research issues. Roma: Unicef; 2002.

26. Parker DL, Fassa AG, Scanlon TJ. Understanding the effects of child labour. In: Fassa AG, Parker DL, Scanlon TJ, organizadores. Child labour a public health perspective. 1 ed. New York: Oxford University Press; 2010. p. 103-121.

27. Arcury TA, Vallejos QM, Schulz MR, Feldman SR, Fleischer Júnior AB, Verma A, Quandt SA. Green tobacco sickness and skin integrity among migrant Latino farmworkers. Am J Ind Med 2008; 51(3):195-203.

28. Peres F, Oliveira-Silva JJ, Della-Rosa HV, Lucca SR. Desafios ao estudo da contaminação humana e ambiental por agrotóxicos. Cien Saude Colet 2005; 10(Supl.):2737.

29. Paraná 2012. Secretaria da Agricultura e Abastecimento. Agrotóxicos no Paraná. [acessado 2012 jan 20]. Disponível em: http://celepar07web.pr.gov.br/agrotoxicos/ bulas.asp

30. Rede Brasileira Contra os Agrotóxicos 2012. Nota técnica: agrotóxicos e câncer. [acessado 2012 maio 20]. Disponível em: http://www.aba-groecologia.org.br/RB $\mathrm{CA} /$ index.php?option $=$ com_content\&view $=$ article \&id=47:agrcancer\&catid $=31$ :saude\&Itemid $=46$

31. Barry KH, Koutros ST, Berndt SI, Andreotti G, Hoppin JA, Sandler DP, Burdette LA, Yeager M, Freeman LE, Lubin JH, Ma X, Zhenq T, Alavanja MC. Genetic Variation in Base Excision Repair Pathway Genes, Pesticide Exposure, and Prostate Cancer Risk. Environ Health Perspect 2011; 119(12):1726-1732.

32. Cockburn M, Mills P, Zhang X, Zadnick J, Goldberg D, Ritz B. Prostate Cancer and Ambient Pesticide Exposure in Agriculturally Intensive Areas in Califórnia. Am J Epidemiol 2011; 173(11):1280-1288.

33. Pignati WA, Machado JMH. O Agronegócio e seus Impactos na Saúde dos Trabalhadores e da População do Estado do Mato Grosso. In: Minayo-Gomes C, Machado JMH, Pena PGL, organizadores. Saúde do trabalhador na sociedade brasileira contemporânea. Rio de Janeiro: Editora Fiocruz; 2011. p. 245-272. 
34. Weichenthal S, Moase C, Chan P. A review of pesticide exposure and cancer incidence in the agricultural health study cohort. Environ Health Perspectiv 2010; 118(8):1117-1125.

35. Ives TJ. Use of dimenhydrinate in the treatment of green tobacco sickness. Drug Intelligence and Clinical Pharmacy 1983; 17(7-8):548-549.

36. Fonseca MGU, Peres F, Firmo JOA, Uchôa E. Percepção de risco: maneiras de pensar e agir no manejo de agrotóxicos. Cien Saude Colet 2007; 12(1):39-50.

37. Trapé-Cardoso M, Bracker A, Grey M, Kaliszewski M, Oncken C, Ohannessian C, Barrera LV, Gould B. Shade tobacco and green tobacco sickness in Connecticut. $J$ Occup Environ Med 2003; 45(6):656-661.

38. Dias EC, Silva TL, Chiavegatto CV, Reis JC, Campos AS. Desenvolvimento de ações de Saúde do Trabalhador no SUS: a estratégias da rede nacional de atenção integral à saúde do trabalhador (Renast). In: Minayo-Gomes $\mathrm{C}$, Machado JMH, Pena PGL, organizadores. Saúde do trabalhador na sociedade brasileira contemporânea. Rio de Janeiro: Editora Fiocruz; 2011. p. 107-122.

39. Organización Mundial de la Salud (OMS). Convenio marco de la OMS para el control del tabaco. Ginebra: OMS; 2004. [acessado 2009 out 20]. Disponível em: http://www.whqlibdoc.who.int/publications/2003/9243591010.pdf

Artigo apresentado em 10/10/2013

Aprovado em 28/02/2014

Versão final apresentada em 10/03/2014 